\section{Control of Bud Sprouting and Elongation in Colored Zantedeschia Tubers by Low-temperature Storage}

\author{
Vered Naor, Jaime Kigel, and Meira Ziv \\ The Hebrew University of Jerusalem, The Robert Smith Institute for Plant \\ Sciences and Genetics in Agriculture, P.O. Box 12, Rehovot, 76100 Israel
}

Additional index words. dormancy

\begin{abstract}
The effect of low-temperature (LT) storage at $10{ }^{\circ} \mathrm{C}$ on dormancy relaxation and budbreak was studied in tubers of colored Zantedeschia. LT storage for 35 or 64 days enhanced budbreak by about 80 days compared to tubers stored at $20{ }^{\circ} \mathrm{C}$. Primary bud elongation did not occur at $10^{\circ} \mathrm{C}$ for 143 days, but took place after the tubers were transferred to $20^{\circ} \mathrm{C}$. Prolonged LT storage enhanced the rate of bud elongation at $20^{\circ} \mathrm{C}$. It is proposed that LT storage enhances dormancy relaxation but, at the same time, inhibits bud elongation in nondormant buds. This dual effect can serve growers in programmed production of year-round forcing of colored calla lily flowers.
\end{abstract}

The rising demand for tubers and flowers of colored Zantedeschia throughout the year is leading to a gradual increase in the production and planting of tubers out of the growing season. The outcome of this trend is the irregular and delayed tuber sprouting frequently observed in the field (Funnell, 1993). This unreliable tuber behavior is probably due to the variation in tuber dormancy. Species of colored Zantedeschia are perennial tuberous geophytes characterized by alternating growth and rest periods (Funnell, 1993). Their tubers usually posses a dominant primary bud (i.e., largest, first sprouting bud), encircled by smaller axillary buds (Funnell etal., 1992, Naor et al., 2005). The total number of the sprouting shoots is probably determined by the strength of apical dominance exerted by the primary shoot (Naor et al., 2005). In colored Zantedeschia tuber dormancy is autonomously and genetically programmed (i.e., endo-dormancy, Lang et al., 1987). However, interaction with environmental conditions during the growth period results in variation in the dormancy level (Carrillo-Cornejo et al., 2003; Funnell, 1993; Naor and Kigel, 2002), probably due to changes in both endo- and eco-dormancy. The stage of endo-dormancy starts before cessation of leaf production, overlaps the stage of foliage collapse and senescence (Halligan et al., 2004), and its duration is dependent on the temperature (i.e., degree-days) during the growth period (Carrillo Cornejo et al., 2003). Under controlled conditions, relatively high daily temperature regimes during plant growth caused a deeper tuber dormancy compared to low temperatures (Naor and Kigel, 2002). In field trials in Israel, shoots emerged after six months in tubers produced under high temperatures in the summer and planted shortly after harvest. In contrast, a shorter rest period of 1 or 2 months was observed in tubers pro-

Received for publication 1 Jan. 2006. Accepted for publication $17 \mathrm{Feb}$. 2006. Tubers were kindly supplied by Mrs. Ziva Gilaad, Jordan Valley Research and Extension Center, Israel. duced under relatively lower temperatures during the winter and spring growth season in greenhouse trials (Naor and Kigel, 2002). Thus, large variation in tuber dormancy can be expected, particularly when Zantedeschia is grown in less favorable conditions. On the other hand, relaxation of tuber dormancy could be manipulated after harvest and this process was affected by storage temperature (Jierwiriyipant and Tjia ,1988). Short-term storage is usually required in Zantedeschia to allow dormancy relaxation before tuber planting (Corr and Widmer, 1988), while long-term low temperature (LT) storage is used with variable results to postpone planting and to prolong the period of cultivation. In their natural habitat, colored Zantedeschia species are exposed to moderately warm rainy summers during the growth period and to cold dry winters during the rest period (Funnell, 1993; Letty; 1973, Mayo et al., 1997). This raises the question whether in Zantedeschia low temperature is required for breaking bud endo-dormancy and/or for inhibiting bud elongation of nondormant buds (eco-dormancy) until the onset of the growth season. Optimization of production programs throughout the year requires a better understanding of the control of these two distinct processes by low temperature. Thus, the objective of our study was to elucidate the separate effects of LT storage duration on the onset and on the rate of bud elongation in tubers of colored Zantedeschia.

\section{Materials and Methods}

Tubers of Black Magic (BM, a Zantedeschia albomaculata (Hook) Baill hybrid) were produced in the Jordan Valley Research and Extension Center, Israel, during spring and summer 2002. Cultivation commenced on 30 Apr. and tubers were harvested at the end of the growth season (20 Sept.). Average greenhouse max-min temperatures were 31 and $24{ }^{\circ} \mathrm{C}$. After harvest, tubers were cleaned and dipped in Captan 1\%, Benlate (benomyl 0.25\%) and Sterner (oxolinic acid $0.15 \%$ ) to prevent fungal and bacterial diseases, and kept dry at $20 \pm 1$ ${ }^{\circ} \mathrm{C}$ for 3 weeks. Tubers weighing 30 to $50 \mathrm{~g}$ were selected for the experiment and stored at $10 \pm 1{ }^{\circ} \mathrm{C}$ (LT storage) and $20 \pm 1{ }^{\circ} \mathrm{C}(75 \%$ $\mathrm{RH}$ ). We studied effects of LT storage duration on tuber dormancy by transferring 20 tubers from 10 to $20{ }^{\circ} \mathrm{C}$ every 4 to 5 weeks during about 5 months (after 35, 64, 108, and $143 \mathrm{~d}$ in $10^{\circ} \mathrm{C}$ storage) and monitored elongation of the dominant primary bud once a week for 7 months. Control tubers were kept at $20 \pm 1{ }^{\circ} \mathrm{C}$ during this period and similarly monitored.

Percent of nondormant (i.e., sprouting) tubers, time to $50 \%$ sprouting, time to end of dormancy (primary bud length $>3 \mathrm{~mm}$ ), and rate of primary bud elongation were calculated for both storage temperatures. The time-course of $\%$ sprouting was a sigmoid function:

$$
\mathrm{Y}=\frac{\mathrm{a}}{1+\mathrm{e}^{\frac{-\left(\text { Days }-\mathrm{X}_{0}\right)}{\mathrm{b}}}}
$$

where Y was percent of sprouting tubers. Time to $50 \%$ sprouting was calculated for actually sprouting tubers only (maximum sprouting tubers was considered $100 \%$ ). The relationship between the duration of LT storage and overall time to $50 \%$ sprouting is shown by a linear regression.

To describe the effect of LT storage on the days to $50 \%$ sprouting after transferring the tubers to $20^{\circ} \mathrm{C}$, we used the equation:

$$
\mathrm{Y}=\mathrm{a}^{*} \mathrm{e}^{\left(-\mathrm{b}^{*} \mathrm{X}\right)}
$$

Rate of bud elongation was calculated from the linear regression describing the time-course of bud elongation:

$$
\mathrm{Y}=\mathrm{aX}+\mathrm{b}
$$

where $Y$ was bud length. The coefficients $a$ and $b$, as well as significance of the regressions were calculated by SigmaPlot software. Standard error for the proportion of sprouting tubers was calculated as

$$
\mathrm{SE}=\sqrt{\frac{\mathrm{p}(100-\mathrm{p})}{\mathrm{n}}}
$$

where $\mathrm{p}$ is the percent of sprouting tubers and $\mathrm{n}$ is total number of tubers.

\section{Results and Discussion}

Primary bud elongation did not occur in tubers stored at $10^{\circ} \mathrm{C}$ for about 5 months (143 d), as found in other Zantedeschia cultivars (Funnell et al., 1988; Funnell and Go, 1993), but took place in tubers stored at $20{ }^{\circ} \mathrm{C}$, or after tubers were transferred from $10^{\circ} \mathrm{C}$ to 20 ${ }^{\circ} \mathrm{C}$. Proportion of sprouting in tubers stored continuously at $20{ }^{\circ} \mathrm{C}$ was lower compared to tubers stored for different periods at $10{ }^{\circ} \mathrm{C}$ and transferred to $20{ }^{\circ} \mathrm{C}: 45 \% \pm 11 \%$ vs. $59 \%$ $\pm 10 \%$ to $77 \% \pm 10 \%$, and tended to increase with longer LT storage (Fig. 1A). The relatively low percent of sprouting in control tubers stored continuously under $20^{\circ} \mathrm{C}$ was probably due to the high temperature conditions under which tubers were produced (Naor and Kigel, 2002). The overall time to $50 \%$ sprouting was shortened by a LT storage period of $35 \mathrm{~d}$ compared to control tubers stored continuously 


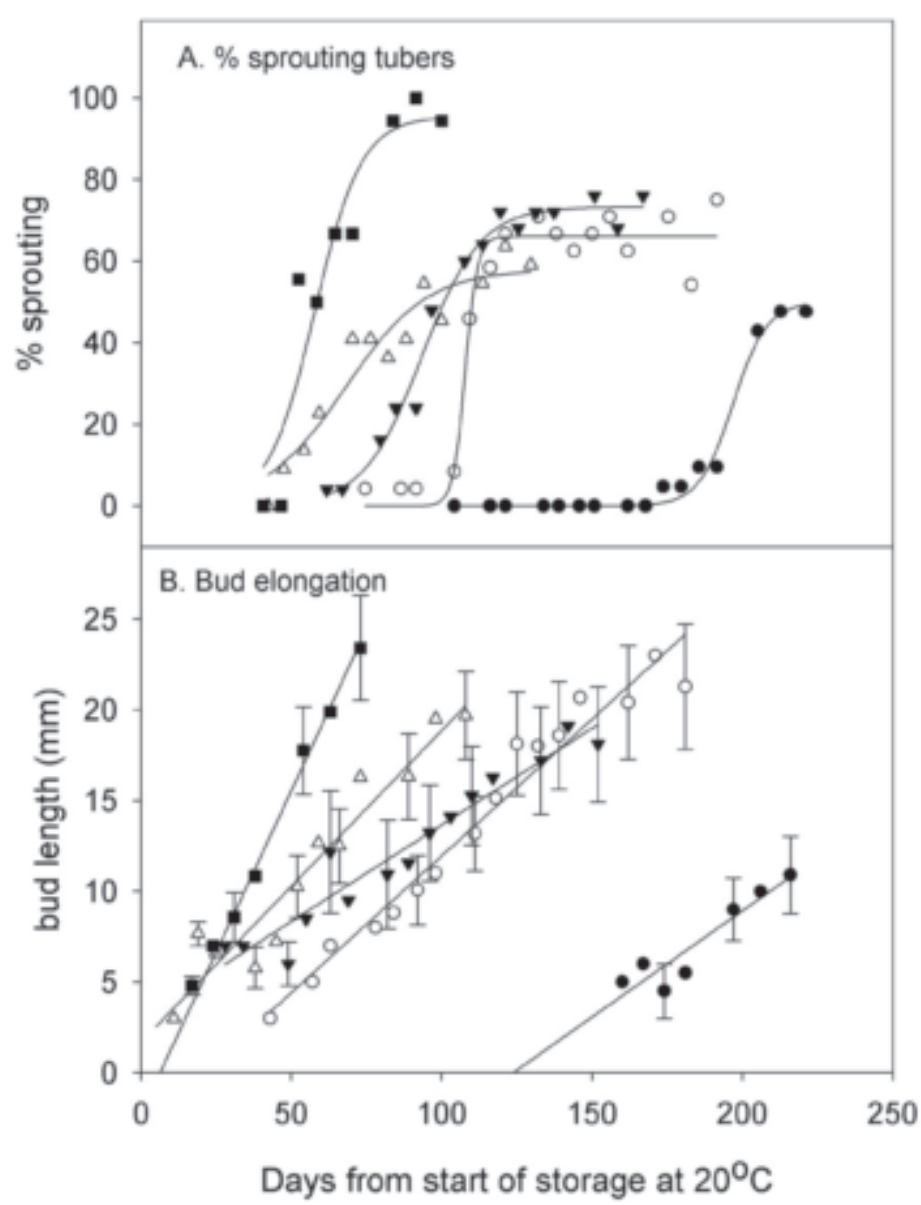

Fig. 1. The effect of the duration of low-temperature storage at $10^{\circ} \mathrm{C}$ on bud sprouting and bud elongation from tubers after their transfer to 20 ${ }^{\circ} \mathrm{C}$. (A) The percentage of sprouting tubers $\left(r^{2}\right.$ $=0.91-0.98 ; p<0.0001)$. (B) Bud elongation $\left(r^{2}=0.89-0.98 ; p<0.0002\right)$. continuous storage at $20^{\circ} \mathrm{C}$; storage at $10^{\circ} \mathrm{C}$ for: $\bigcirc 35$; $64 ; \Delta 108 ; \square 143 \mathrm{~d}$

at $20{ }^{\circ} \mathrm{C}$ (Fig. 2A). However, prolonging the LT storage period beyond $35 \mathrm{~d}$ increased the time to $50 \%$ sprouting (Fig. $2 \mathrm{~A}: r^{2}=0.980$, $p=0.011)$. In contrast, the time required to $50 \%$ sprouting after the transfer to $20^{\circ} \mathrm{C}$ was gradually reduced, by increasing the LT storage period, from 80 to $20 \mathrm{~d}$ (Fig. $2 \mathrm{~A} ; r^{2}=0.970, p$ $=0.002$ ). This time lag was much shorter than the $190 \mathrm{~d}$ required for $50 \%$ sprouting in control tubers continuously stored at $20^{\circ} \mathrm{C}$ (Fig. 2A). Furthermore, LT storage advanced the onset of bud elongation after the transfer to $20{ }^{\circ} \mathrm{C}$ compared to the control tubers (Fig. 1B), and increased the rate of bud elongation, particularly after long (143 d) LT storage (Fig. 2B). Thus, storage at $10^{\circ} \mathrm{C}$ for 35 or $64 \mathrm{~d}$ reduced almost by half the endo-dormancy period of the tubers (Fig. 2A), and onset of bud elongation was about $100 \mathrm{~d}$ earlier than in tubers stored at $20^{\circ} \mathrm{C}$ (Fig. 1B). After 108 and 143 d of LT storage, bud elongation started even earlier after the tubers were transferred to $20^{\circ} \mathrm{C}$, compared to a shorter LT storage period. This indicates that after $108 \mathrm{~d}$ of LT storage the low temperature was inhibiting bud elongation of already nondormant buds (i.e., eco-dormancy). Therefore, sprouting in tubers stored at $10{ }^{\circ} \mathrm{C}$ for in these experiments.

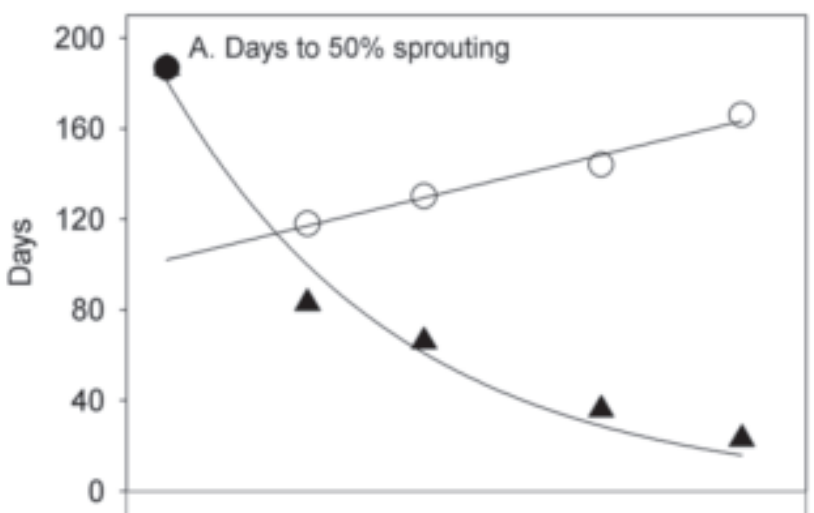

B. Elongation rate

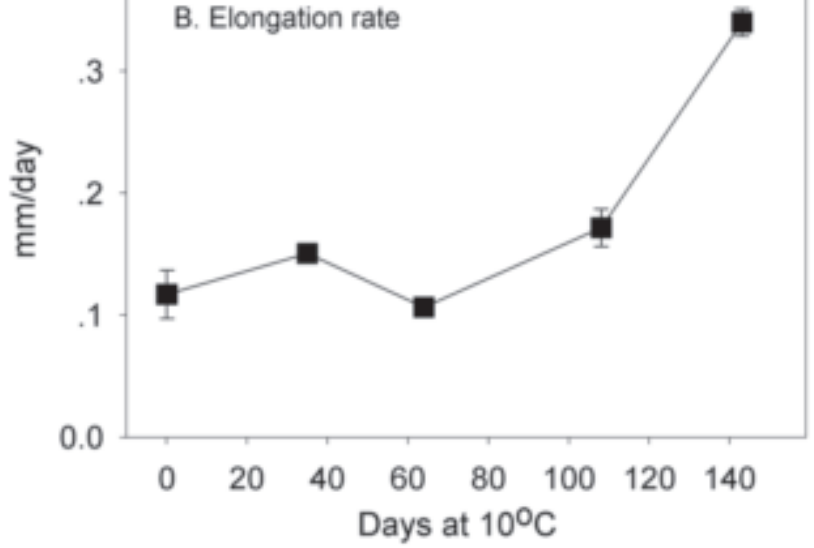

$143 \mathrm{~d}$ was delayed and started along with tubers stored continuously at $20{ }^{\circ} \mathrm{C}$ (Fig. 2A). In contrast to our results, Goto et al. (2005) reported lack of LT storage effect on dormancy relaxation in Zantedeschia. This can be attributed to an initial weak dormancy in tubers produced at optimal growth temperature, as well as to the short (1 to 4 weeks) LT storage duration used

According to Lang et al. (1987), endodormancy is defined as growth arrest in meristematic tissues under favorable conditions, while eco-dormancy is defined as growth retardation due to nonfavorable environmental conditions. According to these definitions it can be concluded that LT storage has a dual action on the sprouting of dormant tubers of colored Zantedeschia. On one hand, it enhances relaxation from endo-dormancy and advances the onset of primary bud elongation at temperatures allowing bud growth (i.e., 20 $\left.{ }^{\circ} \mathrm{C}\right)$. On the other hand, it inhibits growth in nondormant buds (i.e., eco-dormancy). Both actions are probably of adaptive value for wild Zantedeschia species, since they allow synchronization of the growth cycle with seasonal climatic changes in the natural habitat. On the practical side, control of dormancy relaxation and bud elongation by LT storage can be used for production programs. The limited ability to control tuber dormancy in Zantedeschia has prevented growers from year round tuber and flower production, in spite of the fact that colored Zantedeschia does not require flowering induction by specific environmental or seasonal signals (Funnell, 1993; Naor et al., 2005). The fact that LT storage for various time intervals
Fig. 2. The effect of the duration of low-temperature storage on the time for $50 \%$ sprouting tubers (A) and on primary bud elongation rate (B). Days to $50 \%$ sprouting: control tubers from start of experiment; $\bigcirc$ tubers in storage at $10{ }^{\circ} \mathrm{C}\left(r^{2}\right.$ $=0.98 ; p=0.011) ; \boldsymbol{\Delta}$ after transfer from $10^{\circ} \mathrm{C}$ to $20{ }^{\circ} \mathrm{C}\left(r^{2}=0.97 ; p=0.002\right) ; \square$ rate of bud elongation $\left(r^{2}=0.9 ; p=0.1\right)$.

might advance or postpone bud sprouting should increase the flexibility of production systems of colored Zantedeschia. Even though prolonged LT storage has been reported to reduce flowering potential, this negative effect can be prevented or ameliorated by a pre-planting tuber treatment with gibberellin (Dennis et al., 1994; Funnell et al., 1988).

\section{Literature Cited}

Carrillo Cornejo, C.P., K.A. Funnell, D.J. Woolley, and B.R. MacKay. 2003. Heat units may explain variation in duration of bud dormancy in Zantedeschia. Acta Hort. 618:469-475.

Corr, B.E. and R.E. Widmer. 1988. Rhizome storage increases growth of Zantedeschia elliottiana and Z. rehmannii. HortScience 23(6):1001-1002.

Dennis, D.J., J. Doreen, and T. Ohteki. 1994. Effect of gibberellic acid 'quick-dip' and storage on the yield and quality of blooms from hybrid Zantedeschia tubers. Scientia Hort. 57:133-142.

Funnell, K.A.1993. Zantedeschia, p. 683-704. In: A. De Hertogh and M. Le Nard (eds.). Physiology of flowering bulbs. Elsevier, Amsterdam, The Netherlands.

Funnell, K.A. and A.R. Go. 1993. Tuber storage, floral induction, and gibberellin in Zantedeschia. Acta Hort. 338:168-176.

Funnell, K.A., B.R. Mackay, and C.R.O. Lawoko. 1992. Comperative effects of promalin and $\mathrm{GA}_{3}$ on flowering and development of Zantedeschia 'galaxy'. Acta Hort. 292:173-178. 
Funnell, K.A., B.O. Tjia, C.J. Stanley, D. Cohen, and J.R. Sedcole. 1988. Effect of storage temperature, duration, and gibberellic acid on the flowering of Zantedeschia elliottiana and Z. 'Pink Satin'. J. Amer. Soc. Hort. Sci. 113(6):860-863.

Goto, T., K. Kawajiri, Y. Kageyama, and K. Konishi. 2005. Flowering of Zantedeschia rehmannii Engl. as affected by combination of tuber storage temperature and duration. Acta Hort. 673:273-277.

Halligan, E.A., I. R. Brooking, K.A. Funnell, and J.L. Catley. 2004. Vegetative and floral shoot development of Zantedeschia 'Black Magic'. Scientia Hort. 99(1):55-65.

Jierwiriyipant, U. and B. Tija. 1988. Storage temperature and duration affecting subsequent growth and flowering of Zantedeschia elliotiana. HortScience 23:749.

Lang, G.A., J.D. Early, G.C. Martin, and R.L. Darnell. 1987. Endo-, para-, and ecodormancy: Physiological terminology and classification for dormancy research. HortScience 22:371-377.

Letty, C. 1973. The genus Zantedeschia. Bothalia 11(1-2):5-26.
Mayo, S.J., P.C. Boyce, and J. Bogner. 1997. The genera of Araceae, p. 2-316. Royal Bot. Gardens, Kew.

Naor, V. and J. Kigel. 2002. Temperature affects plant development, flowering and tuber dormancy in calla lily (Zantedeschia). J. Hort. Sci. Biotechnol. 77(2):170-176.

Naor, V., J.Kigel, and M.Ziv. 2005. A Developmental pattern of flowering in colored Zantedeschia spp: effects of bud position and gibberellin. J. Plant Growth Regulat. 23(4):269-279. 